\title{
As escritas corporais da caixinha de música: Educação Infantil
}

\section{Bodily scripture from the speakers of the music box: Early Childhood Education}

\author{
Alice Medina ${ }^{1}$
}

\begin{abstract}
RESUMO
O presente estudo foi desenvolvido no Centro de Educação Infantil em Brasília, no Distrito Federal, com crianças e baseado na expressão corporal no contexto de pertencimento da infância. $\mathrm{O}$ objetivo do estudo foi verificar a expressão corporal baseada na escuta musical e na representação e expressão corporais das crianças da Educação Infantil, baseada na relação entre a caixinha de música e a livre expressão como forma de linguagem e de comunicação. Em relação à metodologia utilizada, foi um estudo qualitativo-descritivo com o registro da expressão corporal de cada criança. Participaram das atividades crianças na faixa etária média de cinco anos do Jardim II - Turma com 18 crianças (horário vespertino) de Educação Infantil, após autorização dos responsáveis. Como conclusão observou-se que ao contemplar a livre expressão do corpo infantil, ao se expressar, a criança poderá se desenvolver de forma mais plena e alegre, possibilitando relacionar a dimensão externa com os estímulos apresentados e com a dimensão interna, ou seja, o que ela é a partir dos sentidos e significados de sua identidade, ampliando seu senso de pertencimento.
\end{abstract}

Palavras-chave: corpo; música; Educação Infantil.

\begin{abstract}
This study was conducted at the Children's Education Center, in Brasilia Federal District, with children and it was based on body language in the context that belongs to childhood. The aim of the study was to assess the body language based on musical listening and representation and bodily expression
\end{abstract}

DOI: $10.1590 / 0104-4060.48668$

1 Centro de Ensino Unificado de Brasília. Brasília, Distrito Federal, Brasil. SEPN 707/907. Asa Norte. CEP: 70790-075.E-mail: licinhamedina@gmail.com 
of children from kindergarten, based on the relationship between the music box and the free expression as a form of language and communication. Regarding the methodology used, it was a qualitative-descriptive study with the registration of the body language of each child. Children who participated in the activities were at an average age of five years - Kindergarten II - Class with 18 children (in the afternoon) of Early Childhood Education, after parental consent. As a conclusion it was observed that when contemplating the free expression of the children's bodies, when they express themselves they may develop more fully and joyfully, making it possible to relate the external dimension with the stimulus and the internal dimension, feeling what they are from the senses and meanings of their identities and increasing their sense of belonging.

Keywords: body; music; Childhood Education.

\section{Introdução}

Um estudo desenvolvido por Nogueira (2003) em um projeto de extensão e cultura relacionado à música e ao desenvolvimento da criança orienta sobre a necessidade de que a escola seja um espaço no qual a música seja utilizada nas atividades de rotina por meio de brincadeiras musicais e eventos promovidos pela escola. Mesmo antes de nascerem, as crianças ainda no útero materno respondem a estímulos sonoros.

Em relação ao desenvolvimento cognitivo, o mesmo estudo acima citado relata que tanto por meio do aprendizado de um instrumento ou pela apreciação ativa pela escuta, ocorrem estímulos cerebrais potencializando áreas relacionadas às emoções, cognições e físicas. Antes de nascerem, reações, audição e movimentos, entre outros, são registrados como fatores de desenvolvimento do bebê, contribuindo com suas características físicas, cognitivas e emocionais.

Música e emoção, corpo como manifestação de existência, construindo, transformando e recordando memórias, histórias e saberes, como a apropriação feita por Fanny Abramovich:

Ò ciranda-cirandinha, vamos todos cirandar, uma volta, meia volta, volta e meia vamos dar, quem não se lembra de quando era pequenino, de ter dadas as mãos pra muitas outras crianças, ter formado uma imensa roda e ter brincado, cantado e dançado por horas? Quem pode esquecer a hora do recreio na escola, do chamado da turma da rua ou do prédio, pra can- 
tarolar a Teresinha de Jesus, aquela que de uma queda foi ao chão e que acudiram três cavalheiros, todos eles com chapéu na mão? E a briga pra saber quem seria o pai, o irmão e o terceiro, aquele pra quem a disputada e amada Teresinha daria, afinal, a sua mão? E aquela emoção gostosa, aquele arrepio que dava em todos, quando no centro da roda, a menina cantava: "sozinha eu não fico, nem hei de ficar, porque quero o... (Sérgio? Paulo? Fernando? Alfredo?) para ser meu par”. E aí, apontando o eleito, ele vinha ao meio pra dançar junto com aquela que o havia escolhido... Quanta declaração de amor, quanto ciuminho, quanta inveja, passava na cabeça de todos. (ABRAMOVICH, 1985, p. 59).

A instituição escolar é um local no qual as aprendizagens são múltiplas, portanto, seria indicado que pudessem ser amplas e significativas para as crianças. Os estímulos e as referências familiares e escolares são fundamentais no processo de desenvolvimento infantil e interferem de forma significativa em suas escolhas. O estudo de Caetano e Caetano (2016, p. 103) apresenta essa questão quando assevera que a criança é "[...] um ser em desenvolvimento, que será constituído a partir de sua relação com o meio em que vive e com as instituições as quais frequenta".

Para que as crianças possam se desenvolver de forma ampla e integralmente, família e escola necessitam de orientações sobre os vários aspectos relacionados aos processos de desenvolvimento cognitivo, afetivo e motor da infância.

Segundo a Lei de Diretrizes e Bases da Educação Nacional (LDB, 1996), o objetivo principal da educação é desenvolver de maneira integral a criança até seis anos de idade, a fim de complementar a ação da família e da comunidade. Segundo o referido documento, o ensino deve ser ofertado em creches ou institutos semelhantes e em pré-escolas. A respeito do desenvolvimento integral infantil.

A LDB (1996) e os Parâmetros Curriculares Nacionais (PCN) - da Educação Física (1997) e da Arte (1997) como referenciais orientam o ensino da dança, da música, do teatro e das artes plásticas.

Por incluir e se caracterizar tais disciplinas por métodos e processos livres, possibilitam que as crianças possam viver diferentes experiências com o próprio corpo e se relacionarem com e no espaço de forma livre com expressão por meio da comunicação corporal, de acordo com Santos, Lucarevski e Silva (2005).

Um estudo desenvolvido por Lino (2010, p. 81) aponta para o valor dos sons produzidos pelas crianças, baseados na improvisação, na livre expressão de comunicação: 
A música das crianças é o barulhar, ação imprevisível e indeterminada que flui na diversidade de um corpo que se lança à sensibilidade de soar... a música não opera somente com sons, mas com a escuta como dimensão poética que invade os tempos livres ou as brechas provisórias da instituição para ressoar singularidades plurais. (LINO, 2010, p. 81).

Uma das questões mais recorrentes em relação à utilização da dança na escola é o emprego de coreografias prontas pelas professoras a fim de atender um calendário de datas comemorativas. Em grande parte das instituições a criança não participa do processo de construção coreográfica causando desinteresse e falta de motivação infantil.

A pesquisa realizada demostrou que a criança é capaz de se expressar e criar, desde que lhe seja dada uma oportunidade. Assim, o presente estudo teve como objeto verificar e registrar a expressão corporal baseada na escuta musical e na representação e expressão corporais das crianças da Educação Infantil, baseada na relação entre a caixinha de música e a livre expressão de cada criança no contexto da infância. A música é um elemento que motiva para a comunicação e a expressão de si pela relação de liberdade criativa no espaço e no tempo, pois ao apropriar-se livremente desses fatores, a criança é capaz de transformar e produzir diferentes relações autorizadas e permitidas em seu momento sob a égide de uma autonomia expressiva para imaginar, criar e realizar.

\section{O corpo da criança}

Em muitas escolas existem demandas específicas relacionando a dança às datas comemorativas, em atendimento e cumprimento ao calendário escolar. Muitas vezes a professora, com ou sem a participação dos alunos, elabora coreografias para serem apresentadas para apreciação de pais, familiares, comunidades e agentes escolares. Na maioria das vezes não há uma participação das crianças nos processos de elaboração coreográficos. Nesse contexto ocorrem orientações variadas para as composições e apresentações das crianças como: escolha da música, temática, sequências de passos, figurinos.

No entanto, a dança e a expressão corporal devem ser utilizadas de forma a permitirem, além da participação ativa das crianças, a possibilidade de dialogar com os saberes e contextos da infância. Para isso, diversos recursos podem ser utilizados, como percussão corporal, músicas, construção de estórias e outros. 
Um dos recursos mais utilizados é a música que poderá ser relacionada à expressão corporal a partir de uma prática interdisciplinar, podendo ser apropriada pelos professores desde a Educação Infantil. Em relação à dimensão interdisciplinar, de acordo com Medina (2012):

A organização da prática pedagógica de maneira lúdica e interdisciplinar poderá contribuir significativamente para ações mais adequadas às necessidades e demandas sociais, caracterizadas como espaços e ambientes dialógicos. Educar exige conhecimento, firmeza e sensibilidade, mas também leveza em ambientes compartilhados com alegria, permitindo, dessa forma, que a educação pulse e brilhe com toda a sua intensidade e luz diante das possibilidades e sonhos, proporcionando e representando a vida em cada aluno ao sorrir. (MEDINA, 2012, p. 437).

Cada indivíduo único e complexo constrói-se pelas relações vividas, percebidas e imaginadas diante dos ambientes e situações históricas, sociais e culturais. Para cada relação haverá uma inscrição física, emocional e cognitiva que traçará seu desenho humano na construção de subjetividades. Propiciar momentos e espaços de escutas humanas favorecendo a interlocução entre aspectos e fatores internos e externos poderá permitir o desenvolvimento de sistemas equilibrados dinamicamente, ou seja, a cada tempo e espaço e pulso, uma nova reorganização estrutural pelos elementos constituintes do tecido vivo.

Segundo Mello (1989), o movimento humano é mais do que simples deslocamento do corpo no espaço: constitui-se em uma linguagem que permite às crianças agirem sobre o meio físico e atuarem sobre o ambiente humano, mobilizando para a expressividade. Em conformidade ao que foi citado pelo autor, Strazzacapa (2001) assevera que o indivíduo age no mundo por meio do seu corpo, mais especificamente por meio do movimento.

A criança, a partir da formação e utilização das diversas manifestações simbólicas - linguagem, imagem mental, brincadeira, desenho representativo, fabulação lúdica -, adquire condições de, gradativamente, ir se percebendo como alguém que constrói a própria história de modo ativo e interativo, segundo Oliveira e Bossa (2007).

A proposição é que cada criança se aproprie e utilize suas linguagens físicas, cognitivas e emocionais a partir do seu repertório histórico, cultural e de saberes em diálogos corporais com a música. A mediação entre a música e as representações sociocorporais serão realizadas pela criança, quando, por meio da música e da livre expressão, ela apropria-se de si, comunica-se e realiza-se como plenamente capaz para dizer, falar com total dignidade de escuta. 
Dos dois aos seis anos, a criança começa a lidar com suas representações. Quanto mais organiza de forma sistemática e consciente suas representações (verbais e imagéticas), mais caminha para o período operatório para compreender sistemas simbólicos como a escrita e o número, de acordo com Oliveira e Bossa (2007). Segundo esses autores, ajustes e adequações devem ser realizados pelo educador observador, pois a criança tem uma natureza espontânea que precisa ser respeitada na infância.

Corsini (1998) relata que a Educação Infantil tem como objetivo primordial atender as necessidades psicossociais da criança, criar condições adequadas para o seu desenvolvimento global, estimulando a criatividade e os aspectos físicos e emocionais. Do zero aos seis anos é a fase em que acontece todo o desenvolvimento do ser humano que implicará no seu perfil individual futuramente.

Posto isso, o presente estudo teve como objetivo promover a escuta musical e a representação corporal das crianças da Educação Infantil, baseada na relação entre a caixinha de música e a livre expressão como forma de linguagem e de comunicação. Entre outros, buscou:

- Considerar e inserir as escritas corporais e as representações das crianças;

- Registrar por meio de filmagens as representações livres e espontâneas das crianças a partir da expressão de si ao ouvir uma música instrumental baseada no som da caixinha de música.

Alguns documentos relacionados à Educação Infantil no Brasil:

- Seminário sobre Educação Infantil, formação profissional e critérios de qualidade para creches e pré-escolas - Belo Horizonte-MG (1994);

- Ministério da Educação/Secretaria de Ensino Fundamental/Coordenação Geral de Educação Infantil (MEC/SEF/COEDI) - Pesquisadores produziram textos e documentos após o Seminário sobre Educação Infantil (1995);

- Lei das Diretrizes e Bases da Educação (LDB) no 9.394 20/12/1996;

- Propostas pedagógicas curriculares de Educação Infantil (1996);

- Parâmetros Curriculares Nacionais (PCN, 1998);

- Referenciais curriculares para Educação Infantil (1998);

- Parâmetros Nacionais de Qualidade da Educação Infantil (PNQEI, 2006 - volume 1 e 2).

Os Parâmetros Nacionais de Qualidade da Educação Infantil (PNQEI, 2006 - volume 1 e 2) apresentam referências para a Educação Infantil a serem utilizadas por creches, pré-escolas e Centros de Educação Infantil, para orientar e promover a igualdade de oportunidades educacionais, considerando as diversidades e desigualdades do território brasileiro e as diversidades culturais. Tem como objetivo em sua elaboração propiciar o cumprimento do preceito consti- 
tucional da descentralização administrativa e de cumprir a meta do Ministério da Educação e Cultura (MEC) de construção coletiva das políticas públicas para a Educação. O documento foi elaborado com a contribuição de secretarias, conselheiros, técnicos, especialistas, professores e outros profissionais.

Os PNQEI (2006 - volume 1 e 2) apontam para questões relevantes na definição de parâmetros de qualidade para a Educação Infantil, apresentando uma concepção de criança, de pedagogia da Educação Infantil e a trajetória histórica do debate sobre a qualidade na Educação Infantil.

Em relação aos Referenciais Curriculares para a Educação Infantil (RCNEI, 1998), direcionado às crianças de zero a seis anos, é indicado que seja utilizado como referência para o trabalho dos professores, diferentemente das Diretrizes Curriculares Nacionais (1998), que apresentam diretrizes obrigatórias a serem inseridas e utilizadas por todas as instituições de Educação Infantil. As Propostas Pedagógicas das Instituições de Educação Infantil devem respeitar, segundo as Diretrizes Curriculares Nacionais:
A. Princípios Éticos da Autonomia, da Responsabilidade, da Solidariedade e do Respeito ao Bem Comum;
B. Princípios Políticos dos Direitos e Deveres de Cidadania, do Exercício da Criticidade e do Respeito à Ordem Democrática;
C. Princípios Estéticos da Sensibilidade, da Criatividade, da Ludicidade e da Diversidade de Manifestações Artísticas e Culturais. (BRASIL, 2010, não p.).

\section{A música no corpo infantil}

É notória a "influência" da música sobre o indivíduo, assim como as possibilidades de sua utilização frente às atividades que poderão utilizá-la das mais diversas formas. Essa influência ocorre por meio da mobilização do sentido auditivo relacionado à percepção humana, que acontece em função de aspectos físicos, cognitivos, emocionais, sociais e culturais que constituem cada pessoa. A música pode ir além dos estímulos sonoros, conforme afirma Cage (1985):

[...] a música não é só uma técnica de compor sons (e silêncios), mas um meio de refletir e de abrir a cabeça do ouvinte para o mundo. [...] Com sua recusa a qualquer predeterminação em música, propõe o imprevisível 
como lema, um exercício de liberdade que ele gostaria de ver estendido à própria vida, pois tudo o que fazemos (todos os sons, ruídos e não sons incluídos) é música. (CAGE, 1985, p. 5).

Desde o ventre materno a criança escuta sons diferenciados como vozes, músicas e sons ambientais. É indicado que ainda na fase intrauterina a mãe proporcione ao bebê momentos de escutas para sons agradáveis e tranquilizadores. Em relação à instituição escolar, várias pesquisas indicam a utilização da música como um meio para o desenvolvimento afetivo e social na infância, indicando atividades que estimulem a criatividade e favoreçam a expressividade da criança. Essas atividades poderão estimular a imaginação, a socialização e a relação com si mesmo e com o outro.

A criança, nos primeiros anos de vida, estabelece relações afetivas, sociais, motoras e cognitivas com o contexto que a cerca. Os familiares contribuem para a construção da identidade infantil a partir dos referenciais que apresentam no convívio com a criança. Na verdade, a música é incluída na vida da criança desde muito cedo, ou seja, nas cantigas de ninar e nas brincadeiras e cantigas de roda. Estudos apontam sobre a importância das atividades e vivências sonoras para o desenvolvimento cognitivo, motor e afetivo das crianças quando da utilização da música.

A música, na educação infantil mantém forte ligação com o brincar. Em algumas línguas, como no inglês (to play) e no francês (jouer), por exemplo, usa-se o mesmo verbo para indicar tanto as ações de brincar quanto as de tocar música. Em todas as culturas as crianças brincam com a música. Jogos e brinquedos musicais são transmitidos por tradição oral, persistindo nas sociedades urbanas nas quais a força da cultura de massas é muito intensa, pois é fonte de vivências e desenvolvimento expressivo musical. (BRASIL, 1998, p. 71).

Ao relacionar a expressão corporal por meio da música, objetivando um desenvolvimento integral da criança, é necessário citar a dimensão psicomotora, que relaciona os aspectos mentais e cognitivos às atividades motoras da criança. Especificamente em relação à questão física na infância, o equilíbrio, a agilidade, a noção de tempo/espaço, além do desenvolvimento da consciência corporal, são elementos motores que poderão ser ativados na ampliação do repertório corporal infantil. 
A criança é capaz de descobrir e aprender com o seu corpo, principalmente se tiver a oportunidade de vivenciar espaços que permitam a criatividade e a ludicidade. A expressão musical e corporal são elementos que podem propiciar momentos extremamente diversificados e ricos no processo de desenvolvimento das crianças.

As crianças integram a música às demais brincadeiras e jogos: cantam enquanto brincam, acompanham com sons os movimentos de seus carrinhos, dançam e dramatizam situações sonoras diversas, conferindo "personalidade" e significados simbólicos aos objetos sonoros ou instrumentos musicais e à sua produção musical. (BRASIL, 1998, p. 52).

Uma questão interessante para ser discutida, ao se considerar o uso da música nos espaços escolares, é o fato de que muitas vezes a professora utiliza a música e a dança para atender exclusivamente a uma demanda do calendário de festividades escolares. Em muitas escolas as crianças sequer participam da escolha da música, e o que é mais preocupante, a coreografia pronta deve ser "aprendida" pelas crianças de maneira mecanizada.

Não é difícil coletar alguns discursos de jovens sobre suas experiências, quando as tiveram, na escola. Uma parte significativa relata o uso de coreografias prontas a fim de atender as datas específicas, que são comemoradas pelas escolas, como, por exemplo, o dia da água, das mães, do índio e a tradicional quadrilha da festa junina. Certamente as professoras que trabalham com as crianças e precisam atender tais demandas da escola, muitas vezes, não percebem o que realmente se dá com a dimensão expressiva das crianças. Passar uma coreografia pronta sem dúvida é bem mais fácil do que construir junto com as crianças, mas ao convidá-las a realizar uma elaboração de forma conjunta, as crianças sentem-se integradas ao processo, criando vínculo com aquilo que realizam, porque o que é construído tem parte delas, tem parte de sua identidade.

\section{A escrita do corpo integral: relato de si}

Diferentes pessoas, diferentes culturas e expressões circulam mantendo vivo o pulso da vida. Cada um, com sua maneira própria de dizer e de contar, insere na narrativa apresentada algo de si. A escrita corporal orienta-se por caminhos no desenho e na comunicação para representar. As crianças observam, contam e expressam... 
Piccolo (1999) lembra que os direitos da criança devem ser considerados. Primeiramente ela deve brincar, viver a ludicidade, com a elaboração de procedimentos pedagógicos adequados à realidade de suas experiências.

Ao elaborar e iniciar um trabalho para Educação Infantil é necessário que o professor se relembre das conceituações básicas, finalidades, objetivos, necessidades bio-psicofisiológicas e fundamentos relacionados a essa faixa etária. $\mathrm{O}$ professor deve orientar-se por meio de sugestões de atividades físicoeducativas, de acordo com Hurtado (1996).

A comunicação e expressão corporal podem acontecer de várias maneiras e formas. A criança se comunica e se expressa principalmente em ambientes que permitem uma atmosfera lúdica e alegre.

Ao ouvir a música, se expressar e dançar, a criança brinca, relaciona, imagina e cria, expressando seus saberes. Segundo Medina (2009):

Os estudos demonstram que há a necessidade de uma educação que privilegie todos os aspectos da educação infantil, e que torne a criança apta a se relacionar com o mundo e com as pessoas, utilizando da melhor forma suas competências. (MEDINA, 2009, p. 81).

Permitir e favorecer ambientes criativos e expressivos é fundamental para o desenvolvimento humano, principalmente infantil. Quanto mais experiências positivas e seguras a criança tiver, maiores possibilidades para a qualidade humana ela terá durante a vida. Toda criança tem saberes que são construídos em suas relações e vivências individuais e sociais. As escritas corporais fazem parte desses saberes e fazeres desenhados nas cenas e situações do cotidiano vivido. A instituição familiar e escolar necessita refletir e discutir sobre os modelos que são utilizados pela sociedade e que efetivamente não contribuem de forma positiva para o desenvolvimento integral e integrado da criança.

Alguns dizem que a música é o oxigênio do espírito, assim como as representações e a dança com os movimentos, a inscrição física. Entretanto, há algo entrelaçado nessas relações, ou seja, espírito e físico constituem-se unidos por um corpo integral que age, realiza, pensa, sonha e vive no seu tempo e espaço.

\section{Metodologia: caminhos e ações}

O estudo realizado foi qualitativo-descritivo e contou com a participação de crianças na faixa etária média de cinco anos do Jardim II, uma turma com 
18 crianças (horário vespertino) de Educação Infantil, após autorização dos responsáveis.

As atividades foram realizadas em um Centro de Educação Infantil localizado em Brasília, no Distrito Federal. A composição coreográfica das crianças aconteceu de forma livre a partir da utilização de músicas infantis.

A metodologia utilizada considerou e inseriu as escritas corporais e as representações das crianças no tempo e no espaço da escola, e registrou, por meio de filmagens, as representações livres e espontâneas das crianças a partir da expressão de si ao ouvir uma música instrumental baseada no som da caixinha de música.

Foram realizados os registros das expressões corporais a partir das músicas por meio de uma filmadora e, posteriormente, todas as imagens foram editadas.

Cronograma e atividades:

Músicas/Expressão corporal e Filmagens:

$1^{\text {a }}$ semana: Oficina - Horário: vespertino.

Atividades de expressão livre utilizando-se músicas instrumentais baseadas na caixinha de música para toda a turma do Jardim II da Educação Infantil;

$2^{\mathrm{a}}$ semana: Filmagens - Horário: vespertino.

Registro fílmico da criança ao ouvir a música.

A partir da música ao fundo cada criança expressou e dançou livremente. Após a edição das expressões corporais foram observadas diferenças significativas em relação ao que foi produzido ou apresentado por cada criança participante. Os registros documentaram desde crianças que ficaram observando a lente de filmagem, olhando paradas, observando a câmera, até crianças que desde o início apresentaram expressões e movimentos de dança de forma desinibida frente à filmagem.

É possível que as diferenças observadas e registradas neste estudo estejam relacionadas, principalmente, à diversidade corporal, social e cultural das crianças que, embora frequentem a mesma turma na Educação Infantil, possuem diferenciadas historicidades pessoais em seus repertórios corporais, emocionais e culturais.

A expressão livre para a existência do movimento ou não partiu da escolha autonômica de cada criança ao decidir sobre o que efetivamente queria fazer ao ouvir a música que estava sendo tocada. $\mathrm{O}$ empoderamento de crianças sobre suas escolhas não deve, contudo, ser confundido com a ausência de limites em relação ao comportamento de um indivíduo socialmente integrado. 


\section{Uma reflexão poética: Qual o lugar do corpo da infância na escola?}

O braço é assim

Não olhem para o lado

Olhem para mim

Tem que ficar ensaiado

É a professora ensaiando

A nova coreografia

É ensaio de verdade

Porque pronta já existia

Olha no parque...

Um menino brincando

Ele sobe e desce

Escorregando...

Hi! O movimento mudou

E agora o que vou fazer?

A professora me olhou

Vou ter que correr

Chama minha atenção

Diz que tenho que aprender

A música é Planeta Água

Todos devem conhecer

Queria correr e brincar...

Como a perna levantar?

Nas danças de datas certas

Os mesmos temas apresentar

Coisa sem graça...

Mas fazer o quê?

A gente tem que dançar

Por isso tenho que aprender

Ano que vem Planeta Água

E sei lá mais o quê! 
Os pais vão assistir

A diretora também

Ela esta sempre a sorrir

Diz que deseja o nosso bem

Queria poder sair

Mas tenho que ensaiar

Vou repetir bem direitinho

Para ensaio terminar

Porque depois vai ser legal

Vou correr e brincar!

\section{Algumas considerações}

O presente estudo foi pautado na expressão e improvisação das crianças para a composição coreográfica, por meio da edição das representações de cada criança ao ouvir uma música instrumental baseada no som da caixinha de música.

O corpo é a representação física, emocional, cognitiva e cultural da existência, dessa forma, e consecutivamente, o meio de comunicação e expressão humana, seja na fase da infância ou na fase adulta.

A pesquisa contemplou a livre expressão do corpo infantil no seu movimento de vida para aquilo que sentir e quiser expressar, no momento em que ouvir uma música, podendo representar desde movimentos de dança, mímica, brincadeiras. até um olhar para a câmera no sentido de conhecê-la, desvendá-la. A proposta do estudo não foi ensinar uma dança e sim registrar as expressões como linguagens a partir dos repertórios emocionais, físicos e cognitivos de cada criança na comunicação sobre si.

Todo corpo precisa ser percebido e entendido como um meio de comunicação e expressão carregado de sentimentos, afetos.

Permitir e oportunizar a livre expressão do corpo infantil para além de coreografias prontas é um direito de apropriação pela criança do seu próprio corpo e a dança é uma possibilidade de caminho singular para essa apropriação.

É importante que a escola se aproprie da dança para além das apresentações em datas comemorativas, já que, como um meio de comunicação, permite às crianças se expressarem de forma mais livre.

A dança e a expressão corporal são entendidas e reconhecidas para além das produções ou elaborações coreográficas como um resultado e produto 
final. Na verdade, as atividades de expressão corporal na escola objetivam o desenvolvimento integral da criança com a apropriação de si para sua ação no mundo. Ao se expressar a criança poderá se desenvolver de forma mais plena e alegre. Possibilita relacionar a dimensão externa com os estímulos apresentados e a dimensão interna, ou seja, o que ela é a partir dos sentidos e significados de sua identidade e ampliando seu senso de pertencimento.

O trabalho de expressão musical não está atrelado à formação de dançarinos e muito menos a bailarinos, ou seja, está intimamente ligado à formação cidadã.

Pelos bancos escolares passarão futuros professores, advogados, engenheiros, médicos e todas as demais profissões que caracterizam e qualificam os profissionais. A dança e a expressão corporal serão atividades sem dúvida que irão corroborar para que cada profissional se aproprie de si mesmo para sua ação no mundo.

\section{REFERENCIAS}

ABRAMOVICH, F. Quem educa quem? São Paulo: Summus, 1985. 141 p.

BRASIL. Diretrizes e Bases da Educação Nacional. Lei no 9.394, de 20 de dezembro de 1996. Estabelece as diretrizes e bases da educação nacional. Diário Oficial da União, Brasília, 23 dez. 1996.

BRASIL. Ministério da Educação e do Desporto. Conselho Nacional da Educação. Diretrizes Curriculares Nacionais para a Educação Infantil. Parecer CEB no 022/98, 17 de dezembro de 1998a.

BRASIL. Ministério de Educação e do Desporto. Referencial Curricular Nacional para Educação Infantil. Brasília: MEC, 1998b.

BRASIL. Secretaria de Educação Fundamental. Parâmetros Nacionais de Qualidade na Educação Infantil. Ministério da Educação - Secretaria de Educação Básica. Brasília, 2006. v. 1 e 2.

BRASIL. Ministério da Educação. Secretaria de Educação Básica. Diretrizes curriculares nacionais para a educação infantil. Secretaria de Educação Básica. Brasília: MEC, SEB, 2010.

CAETANO, M.; CAETANO, M. R. Revista de Zero a seis, Florianópolis: UFSC, v. 18, n. 33, p. 83-107, jan./jun. 2016.

CAGE, J. De segunda a um ano. Tradução de: DUPRAT, Rogério. São Paulo: Hucitec, 1985. $172 \mathrm{p}$. 
CORSINI, C. F. Dificuldade de aprendizagem: representações sociais de professores e alunos. Dissertação (Mestrado) - Faculdade de Psicologia, Puccamp, Campinas, 1998.

HURTADO, J. G. G. M. Educação Física Pré-escolar e Escolar. Uma abordagem psicomotora. 5. ed. Porto Alegre: Edita, 1996. p. 11.

LINO, D. L. Barulhar: a música das culturas infantis. Revista da ABEM, Porto Alegre, v. $24,81-88$, set. 2010 .

MARQUES, I. Dançando na escola. São Paulo: Cortez, 2003. 206 p.

MEDINA, A. M. C. Atividades físicas e lúdicas como fator motivacional para desenvolver as inteligências múltiplas em crianças até oito anos. EDUCERE-Revista da Educação, Umuarama, v. 9, n. 1, p. 81-97, jan./jun. 2009.

MEDINA, A. M. C. Didática Recreativa Matemática: ensino e aprendizagem em uma Escola da Comunidade. Revista Contemporânea de Educação, v. 7, n. 14, ago./dez. 2012.

MELlO, A. M. Psicomotricidade, Educação Física e Jogos Infantis. São Paulo: Ibrasa, 1989.

NOGUEIRA, M. A. A música e o desenvolvimento da criança. Revista da UFG, v. 5, n. 2, dez. 2003. Disponível em: <http://www.proec.ufg.br/revista_ufg/infancia/G_musica. html>. Acesso em: 24 set. 2016.

OLIVEIRA, V. B.; BOSSA, N. A. (Org.). Avaliação Psicopedagógica da Criança de Zero a Seis Anos. Petrópolis: Vozes, 2007. 223 p.

PICCOLO, V. L. N. (Org.). Pedagogia dos esportes. São Paulo: Papirus, 1999.

SANTOS, J. T.; LUCAREVSKI, J. A.; SILVA, R. M. Dança na escola: benefícios e contribuições na fase pré-escolar. Trabalho de Licenciatura (Graduação em Psicologia) - Centro Universitário Filadélfia/UniFil, Londrina, 2005.

STRAZZACAPA, M. Técnicas Corporais - à procura do outro que somos nós mesmos. Revista do Lume, Unicamp, São Paulo, p. 45-51, 2001.

Texto recebido em 28 de setembro de 2016. Texto aprovado em 03 de novembro de 2016. 
